Rev. $A N P(L L$, n. 6/7, p. 141-148, jan./dez. 1999

\title{
UMA ABORDAGEM FONOESTILÍSTICA DOS DISCURSOS DOS PASTORES ELETRÔNICOS
}

Graziela Lemme de Menezes *

\begin{abstract}
RESUMO: Neste artigo, apresentamos uma abordagem fonoestilística dos discursos dos Pastores Eletrônicos. Termo que se refere aos evangélicos que transmitem a palavra da fé através dos meios de comunicação de massa, ou seja, rádio e televisão. $O$ interesse pelo tema deve-se à evidência do avanço recente das religiōes pentecostais no Brasil, o maior país católico do mundo, e, também, ao veículo utilizado para transmitir tal mensagem, isto é, as múdias. Purtimos do pressuposto de que essas duas características conjugadas determinam um estilo sonoro particular, cujos traços buscamos desvendar e analisar.
\end{abstract}

PALAVRAS-CHAVE: discursos religiosos; meios de comunicação de massa; fonoestilistica.

\section{INTRODUÇÃO}

noção de estilo sempre esteve mais relacionada à literatura. Den-
tre as muitas possibilidades de que a lingua escrita dispõe, escolhe-se uma. Tal escolha só é possível porque há a redundância, ou seja, a língua comporta muitos sinônimos, equivalências lexicais, sintáticas (Léon, 1993: 8).

É este o mesmo princípio da fonoestilística - ou "estilo sonoro", segundo as palavras de Pierre Léon (1993: 8). O fonoestilo é fundamentalmente escolha (Léon, 1993: 8). Contudo, o acervo do qual dispomos para compor o "estilo sonoro" é distinto daquele do estilo (textual e discursivo). $\mathrm{O}$ acervo do estilo sonoro é composto por elementos chamados prosódicos, tais como a pausa, a acentuação e, também, a entoação.

* Universidade Federal Fluminense. 
MENEZES, Graziela Lemme de. Uma abordagem fonoestilistica dos discursos...

" $\Lambda$ língua é um sistema de signos convencionais, um código, com o auxílio do qual as mensagens sảo transmitidas" (Léon, 1971: 3). Mensagens essas que podem desempenhar várias funções, mas a sua classificação pode ser reduzida, distinguindo-se duas categorias que englobam a sua diversidade: a primeira categoria refere-se à fonologia, cuja função de seus elementos é representativa; a segunda diz respeito à fonoestilística, que fornece uma "(...) informação suplementar à mensagem representativa (...)" (Léon, 1971: 3).

É esta segunda categoria que, ao fornecer uma informação suplementar, permite que sejam transmitidas as nuances do estado de espírito do falante como, por exemplo, o mau humor, a ironia, a alegria, a cólera, a tristeza etc., sem que ele empregue nenhuma palavra que se refira diretamente a essas emoções. $\Lambda$ forma como essas e outras emoções são expressadas pelo falante e percebidas pelo ouvinte também estão organizadas num código, pois do contrário elas não poderiam ser compreendidas por este último.

$\Lambda$ proposta deste trabalho foi investigar a fala de uma nova expressão religiosa - esta que vem se tornando alvo de abordagens diversificadas no âmbito das Ciências Sociais, mas que ainda não havia sido tratada pela Lingüística -, e que se tornou uma opção de fé num país, o Brasil, que é conhecido como a maior nação católica do mundo (Fernandes, 1998: 7).

Para a Lingüística, as religiōes derivadas do Protestantismo, apresentam uma característica especialmente instigante, isto é, desde o seu início na Europa, ele é conhecido como a religião da Palavra. Continuando esta origem, o Pentecostalismo mantém esta particularidade. $\Lambda$ ssim, "(...) é na comunicação verbal que coloca a ênfase da experiência religiosa (...), com palavras de poder transformador. Palavras que curam e interferem até mesmo nas condiçōes materiais da vida em sociedade (...)" (Fernandes, 1996: 30).

$\Lambda$ igrejas sobre a insígnia do Pentecostalismo reúnem hoje cerca de 32 milhões de fiéis no Brasil, cerca de 18\% da população. Em outras 
palavras, o perfil do maior país católico do mundo está mudando com este "(...) intrigante fenômeno de sucesso cultural" (Fernandes, 1996: $3)$.

Se levarmos em conta este imenso contingente de convertidos, a uma velocidade vertiginosa, uma outra face da Palavra da Fé precisa ser revelada: a força da Palavra do Pregador, seu poder de comunicação, pois ela é o veículo do convencimento.

O objeto de nossa pesquisa é o televangelismo. Termo referente aos programas de televisão em que pastores e bispos das Igrejas Pentecostais transmitem a palavra religiosa ${ }^{1}$. Assim, temos duas especificidades num mesmo discurso: a religião e a mídia. Estamos interessados nesta linguagem religiosa veiculada por este canal.

\section{METODOLOGIA}

Os parâmetros prosódicos considerados como reveladores da diversidade dos usos de uma língua são os acentos, a duração, as pausas e a entoação. Portanto, são os parâmetros que compõem qualquer ato de fala, mas que, em nosso caso particular, desempenha um papel especial.

Portanto, partindo-se da consideração de que a função básica

"(...) dos elementos prosódicos é a de realçar ou reduzir certas partes do discurso, para que daí resulte um mapeamento do discurso, que mostra ao interlocutor como dar valor e importância a certos elementos e tratar com menos importância outros (...)" (Cagliari, 1993: 4647).

Entedemos o discurso religioso como "(...) aquele em que fala a voz de Deus: a voz do padre - ou do pregador, ou, em geral, de qualquer representante seu - é a voz de Deus" (ORL_ANDI, 1996: 243) [grifos da autora]. 
MENEZES, Graziela Lemme de. Uma abordagem fonoestilistica dos discursos...

Procuramos desvendar como esses elementos se apresentam e se organizam num discurso específico, ou seja, num outro nível, o uso voluntário (o seu caráter especial) deles, por parte do falante, como uma forma de particularização de um determinado grupo (profissional, religioso, político etc.).

Os dois aspectos conjugados - discurso religioso veiculado pelas mídias - vão se manifestar sobre a cadeia falada e, assim, os fenômenos prosódicos, aos quais nos referimos, irão se adequar a estas estruturas de comunicação de modo mais ou menos "premeditado". Em outras palavras, o locutor que estamos investigando deverá, em princípio, empregar os elementos prosódicos de uma forma convencionalizada e "controlada" para que ele possa se ajustar às estruturas de comunicação e à situação já especificadas.

O nosso corpus compõe-se de gravações de programas evangélicos, feitas da televisão e do rádio, entre os meses de fevereiro e julho do ano de 1997, perfazendo um total de sessenta e dois minutos e sete informantes, quatro do sexo feminino e três do sexo masculino.

Transcrevemos auditivamente todas essas gravações, embora, em

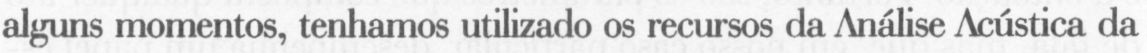
voz, para que pudéssemos detectar melhor os principais índices acústicos da fala de nossos informantes. Foi-nos permitido, também, com tais recursos, medir as durações das pausas, das vogais e consoantes $O$ programa que utilizamos para esses fins foi o WinPitch, criado pelo foneticista e engenheiro francês Philippe Martin.

$\mathrm{O}$ WinPitch, por fornecer em tempo real e de forma simples as medidas da intensidade, duração e da freqüência do fundamental - parâmetro este que, para o nosso estudo, é muito importante, pois, como Martin (1996) afirma, a medida de $\mathrm{F}_{0}$ no sinal da fala é ainda uma das técnicas essenciais na pesquisa em fonética experimental, ressaltando as suas aplicações no campo da fonoestilística. 


\section{ANÁLISE DO CORPUS}

Consideramos cinco níveis de freqüência e quatro níveis de intensidade, pois, em alguns casos, esse último parâmetro mostrou-se relevante, do ponto de vista fonoestilístico, na medida em que foi ele o responsável pelo destaque dado a um determinado segmento do discurso. Esses níveis foram determinados a partir da média das medidas da intensidade e freqüência realizadas nos traçados.

Segundo Quillis (1993) a análise dos níveis é necessária para descrever os pontos pertinentes entre os quais se move a melodia da língua falada.

Assim, percebemos como muito alto o nível de freqüência igual ou superior a $300 \mathrm{~Hz}$, e baixo quando este índice não ultrapassou os $149 \mathrm{~Hz}$. Com o estabelecimento desses níveis de freqüência, marcamos na curva da entoação de todo o corpus os pontos-chave.

Quanto à intensidade, utilizamos o critério idêntico ao da freqüência. $\Lambda$ ssim, alto foi considerado o nível que fosse igual ou superior a $35 \mathrm{~dB}$ e baixo até $20 \mathrm{Db}$, como é mostrado na figura abaixo.

\begin{tabular}{|l|l|c|c|}
\hline FREQÜÊNCIA & \multicolumn{3}{|c|}{ INTENSIDADE } \\
\hline NÍVEL 5 & Muito alto & $300 \mathrm{~Hz}$ & \\
\hline NíVEL 4 & Alto & $250 \mathrm{~Hz}$ a $299 \mathrm{~Hz}$ & $35 \mathrm{~dB}$ \\
\hline NÍVEL 3 & Médio-alto & $200 \mathrm{~Hz}$ a $249 \mathrm{~Hz}$ & $28 \mathrm{~dB}$ a 34dB \\
\hline NÍVLL 2 & Médio-baixo & $150 \mathrm{~Hz}$ a $199 \mathrm{~Hz}$ & $21 \mathrm{~dB}$ a $27 \mathrm{~dB}$ \\
\hline NÍVEL 1 & Baixo & Até $199 \mathrm{~Hz}$ & Até 20dB \\
\hline
\end{tabular}

Fig. 1: Niveis de freqüência e intensidade.

$\Lambda$ partir das curvas da entoação e do esquema de níveis de intensidade, fornecidos pelo WinPitch, pudemos observar alguns fenômenos interessantes no que se refere à oscilação da freqüência. 
MENEZES, Graziela Lemme de. Uma abordagem fonoestilística dos discursos...

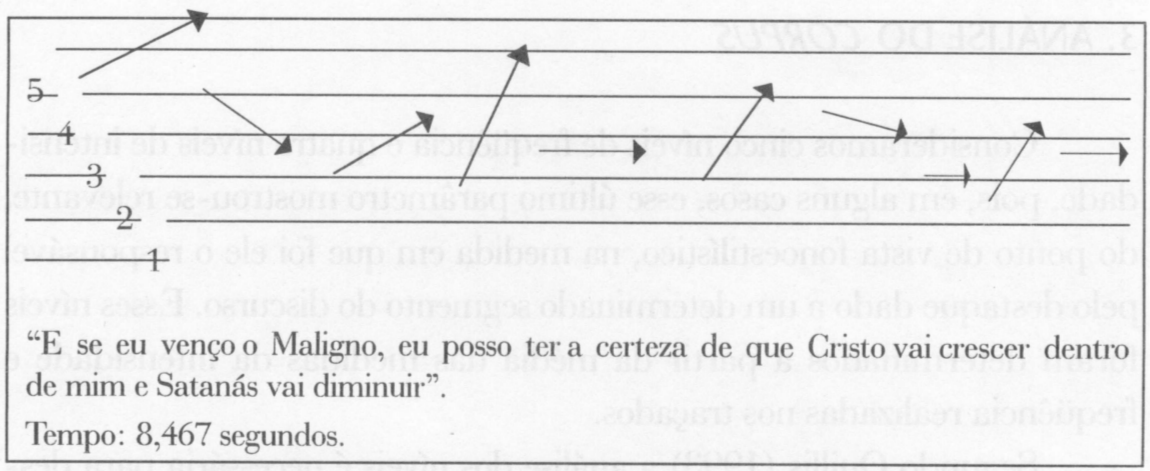

Fig 2: Oscilações de freqüência. Medidas fornecidas pelo WinPitch.

\begin{tabular}{|l|c|c|c|c|c|c|c|}
\hline Vogais & $\mathrm{i}$ & yew & $\leftarrow$ & $\omega$ & ew & $`$ & $\mathrm{e}$ \\
\hline $\mathbf{F}_{\mathbf{0}}(\mathbf{H z})$ & 278 & $278-175$ & $387-559$ & 175 & $248-125$ & 245 & 250 \\
\hline $\mathbf{I}(\mathbf{d B})$ & 29 & 29 & 29 & 26 & 33 & 34 & $29-35$ \\
\hline $\mathbf{D}(\mathbf{s})$ & 0,090 & 0,180 & 0,236 & 0,019 & 0,041 & 0,084 & 0,050 \\
\hline
\end{tabular}

\begin{tabular}{|l|c|c|c|c|c|c|c|c|}
\hline Vogais & $\mathrm{a}^{\mathrm{j}}$ & $\mathrm{e}$ & $\mathrm{e}$ & $\mathrm{e}$ & $\mathrm{I}$ & $\mathrm{a}^{\mathrm{j}}$ & $\mathrm{a}^{\mathrm{j}}$ & $\mathrm{i}$ \\
\hline $\mathbf{F}_{\mathbf{0}}(\mathbf{H z})$ & $170-236$ & 340 & $138-107$ & 270 & $220-170$ & $199-207-180$ & $160-170$ & $180-175$ \\
\hline $\mathbf{I}(\mathbf{d B})$ & 32 & $31-29$ & $31-25$ & 33 & $23-25$ & $30-19-32$ & 28 & $27-26$ \\
\hline $\mathbf{D}(\mathbf{s})$ & 0,289 & 0,087 & 0,274 & 0,090 & 0,100 & 0,226 & 0,180 & 0,049 \\
\hline
\end{tabular}

Fig. 3: Freqüência, intensidade e duração correspondentes às vogais da frase "E se eu venço omaligno, eu posso ter a certeza de que Cristo vai crescer dentro de mim e Satanás vai diminuir".

A princípio, a análise desses contornos, com as suas bruscas subidas e descidas de $\mathrm{F}_{0}$, poderia levar à constatação de um estado de espírito muito próximo de uma explosão colérica, de emoção em estado bruto. Contudo, o que se pôde observar na fala dos pastores estudados é uma "estilização da emoção" (Léon, 1993: 135), pois as alterações prosódicas aparecem “(...) particularmente nos pontos de informação do enunciado, na palavra-chave, (...) na evolução da sílaba acentuada (...)" (Léon, 1993: 136).

Outros recursos prosódicos empregados pelos informantes estudados foram o alongamento (silábico, consonantal e vocálico); o contraste alongamento versus encurtamento entre sons contíguos; a oscilação de 
Rev. ANPOLL, n. 6/7, p. 141-148, jan./dez. 1999

freqüência intensa, numa mesma vogal, ditongo ou tritongo; a manutenção de freqüência em um nível alto ou baixo, por um período considerável. Observamos, também, a elevação da voz no final de frases assertivas; a passagem do nível alto ao baixo da intensidade e/ou da freqüência num curto espaço de tempo.

Contudo, o recurso mais utilizado pelos informantes foi mesmo o contraste entre frequiências altas e baixas. Essas variações de altura ocorreram, em sua maioria, num curto espaço de tempo. Em princípio, a curva da entoação nos pareceu ser o fator mais evidente na caracterização desses discursos.

Assim, o conjunto desses recursos e o seu emprego, sumariamente descritos acima, caracterizam, fonoestilisticamente, os discursos dos Pastores Eletrônicos, cuja função é basicamente persuasiva, à semelhança dos discursos político e propagandístico - já analisados por pesquisadores como Pierre Léon, Monique Callamand, Danièle Duez, dentre outros -, ou seja, "(...) aquele que fala busca persuadir aquele que ouve, (...) conquistar a parceria. [Por outro lado, quem ouve e, conseqüentemente, interpreta a mensagem verbal] investe quem fala da credibilidade, (...) como portador de um dizer verdadeiro" (Teixeira, 1996: 95).

RESUMÉ: Nous avons traiter ici sur les aspects phonostylistique des les discours évangeliques véihiculés à travers de les medias. Nous partons de le principe que ily a des caractéristiques prosodiques particulères qui vont permettre d'indentifier ces discours, tels quels l'intonation, les pauses, les alongements syllabiques etc.

MOTS-CLES: discours religieux; medias; phonostylistique. 
MENEZES, Graziela Lemme de. Uma abordagem fonoestilistica dos discursos...

\section{BIBLIOGRAFIA}

ALVES, Rubem A. (1982) Protestantismo e Repressão. Série Ensaios, n. 55. São Paulo: Ática.

CAGLIARI, Luiz Carlos. (1993) "Da importância da prosódia na descrição dos fatos gramaticais" In ILARI, R. (org.). Gramática do Português Falado: níveis de análise lingüística. v. II, 2. ed, Campinas: Unicamp, p. 39-64.

CALLAMAND, M. (1987) "Analyse des marques prosodiques du discours". In Études de Linguistique_Appliquée. n. 66, Avril-Juin, p. 49-70.

DUEZ, Danièle. (1991) La Pause dans la Parole de l'Homme Politique. Paris: CNRS.

FERNANDES, Rubem César (coord.). (1998) Novo Nascimento: os evangélicos em casa, na Igreja e na política. Rio de Janeiro: ISER.

FLORIG, Evelyne. (1993) Le Français aux Actualités: étude prosodique. Strassbourg: Université des Sciences Humaines de Strassbourg.

FÓNAGY, Ivan. (1976) "Prosodie professionnelle et changements prosodiques". In Le Français Moderne. v. 44, p. 193-228.

LÉON, Pierre R. (1993) Traité de Phonostylistique. Paris: Nathan Université.

MARTIN, Phillippe. (1996) "Les problèmes de l'intonation: recherches et applications". In Langue Française. n. 19, p. 4-32, 1996.

MATTA MACHADO, Mirian Therezinha da. (1997) Normas de Transcrição Fonética. Inédito.

ORO, Ari Pedro. (s/d) "O discurso dos pregadores eletrônicos". In Cadernos de Antropologia, n. 2. Porto Alegre: UFRGS, p. 25-38.

QUILIS, Antonio. (1993) Tratado de Fonología y Fonética Españolas. Madrid: Gredos.

TEIXEIRA, Lúcia. (1996) As Cores do Discurso: análise dos discurso da crítica de arte. Niterói: EDUFF. 